\title{
Antioxidative effects of mulberry foliage extract in African catfish diet
}

\begin{abstract}
This study was carried out to evaluate the antioxidative potential and quality of the meat of African catfish fed mulberry foliage extract (MFE). A total of 360 juvenile African catfish $(8.4 \pm 0.2 \mathrm{~g})$ were fed four diets namely, basal diet (control), MFE-2 (2 g MFE kgī 1), MFE-5 (5 g MFE kgī 1) and MFE-7 (7 g MFE kgī 1) for 60 days. At the end of the experiment, muscles were excised, vacuum-packaged and conditioned for 0, 7 and 14 days in a chiller $\left(4^{\circ} \mathrm{C}\right)$. The meat from fish fed MFE-5 and MFE-7 had significantly $(\mathrm{P}<0.05)$ greater total phenols content than the other dietary groups. This value reduced $(\mathrm{P}<0.05)$ during storage. The DPPH-scavenging effect of MFE-7 increased $(\mathrm{P}<0.05)$ compared with the others. It decreased $(\mathrm{P}<0.05)$ during storage. The lowest POV was revealed $(\mathrm{P}<0.05)$ in MFE-7. The 2-thiobarbituric acid-reactive substances (TBARS) and peroxide value (POV) increased (P < $0.05)$ during storage. The $\mathrm{pH}$ value was significantly $(\mathrm{P}<0.05)$ higher in MFE supplemented diets than in the control group. It is concluded that MFE at the concentration of $7 \mathrm{~g} \mathrm{~kg} \overline{1} 1 \mathrm{DM}$ is potential dietary antioxidant supplements, to improve the quality of fish meat.
\end{abstract}

Keyword: African catfish; Mulberry foliage extract; Antioxidative potential; Meat composition; Meat quality 